\title{
PAPEL DE TUTORES EM CURSOS DESENVOLVIDOS NA MODALIDADE DE EAD
}

Mário César Carvalho - Fac. de Castanhal-PA - carvalhomario@yahoo.com.br

Luis Roque Klering - PPGA/EA/UFRGS - lrklering@ via-rs.net

Christine da Silva Schröeder - PPGDR//UNISC - christine1004sch@ gmail.com

\section{RESUMO}

O artigo tem por objetivo identificar e caracterizar o papel de tutores em cursos de Educação a Distância (EAD) mediados pela internet, enfocando o caso de um curso de graduação em Administração, modalidade a distância, desenvolvido numa Escola de Administração de uma Universidade Federal do sul do Brasil (ESCOLA/UFSB), durante o período de 2006 a 2011. A motivação para a realização deste estudo surgiu das dificuldades enfrentadas pelas instituições de ensino superior em capacitar profissionais para atuar como tutores em cursos on-line, segundo agenda e regras de atuação previamente conhecidas e definidas. Neste contexto, a pesquisa parte de um referencial teórico sustentado pela EAD, sobre o papel de tutores em cursos desenvolvidos na modalidade de EAD. Foram entrevistados 23 atores do curso objeto da pesquisa, bem como analisados documentos do curso. $O$ estudo conclui que os tutores são os protagonistas no atendimento aos alunos, assumindo, de fato, um papel de professores-administradores perante suas turmas. Deparam-se com situações complexas - eventos - em que precisam tomar decisões acertadas, mobilizando e combinando os recursos (pessoais, de conhecimentos ou de habilidades) adequados a cada circunstância do processo de ensino a distância.

Palavras-chave: competências, educação a distância, tutor.

\section{THE ROLE OF TUTORS IN ONLINE EDUCATION PROGRAMAS}

\begin{abstract}
The purpose of the article is to identify and characterize the role of tutors in online Distance Education programs. To that end, we analyzed the case of a distance Business undergraduate program developed at a School of a southern Brazilian Federal University (SCHOOL/SBFU), from 2006 to 2011. The reason to conduct this study emerged from the hardships faced by higher education schools when training people to serve as tutors in online programs, according to previously known schedules and operating rules. In such context, the research is based on a distance education-related literature review, especially about the role of tutors in online Distance Education programs. Twenty-three players in the program analyzed were interviewed, and program documents were examined as well. The study concludes that tutors are leading characters in the interaction with students, and actually take on the role of instructors/administrators before their classes. They come across complex situations events - in which they must make wise decisions by drawing on and combining (personal, knowledge- or skill-related) resources suitable to each circumstance of the distance education process.
\end{abstract}

Key words: competences, distance education, online tutor. 


\section{INTRODUÇÃO}

A EAD tem estado cada vez mais presente nas instituições de ensino superior (IES), onde o ensino, mediado principalmente pela internet, vem exercendo um papel cada vez mais importante no desenvolvimento de competências e no aumento das oportunidades de acesso ao ensino. Via Universidade Aberta do Brasil (UAB), o governo federal já formou milhares de profissionais em todo Brasil, em diferentes cursos, por meio de acordos de cooperação técnica com universidades brasileiras e outras instituições. O curso de graduação em Administração, desenvolvido na modalidade de EAD pela ESCOLA/UFSB, entre os anos de 2006 e 2011, objeto desse estudo, foi um de vários cursos de Administração oferecidos de forma semelhante naquele período em diversos outros Estados do Brasil e constituiu uma oportunidade importante para profissionais residentes no interior do país, ou com outras restrições de acesso ao ensino presencial regular, concluírem o ensino superior.

As equipes dos programas de EAD, de forma geral, são interdisciplinares. São constituídas por profissionais com diferentes papeis: professores, tutores, designers, técnicos de informática, gestores internos, coordenadores de polos de ensino, auxiliares de secretaria etc. Todos tem alguma responsabilidade direta para o sucesso dos cursos. Todavia, mesmo entendendo que o papel de cada categoria de profissionais é importante, nesta pesquisa é dado destaque especial para o papel dos tutores, que são os profissionais que interagem diretamente com os discentes no meio virtual. Cabe a eles, dentre outras atribuições, colocar em prática as possibilidades de interação entre os alunos para consolidar a noção de turma, facilitando a troca de informações e a vivência de situações coletivas de aprendizagem.

Mas qual é, afinal, o papel de um tutor? Quais são suas funções, tarefas e responsabilidades? O que significa ser um tutor?

Questões como essas motivaram a realização do presente estudo. O seu objetivo é, portanto, caracterizar o papel do tutor para a atuação em programas de EAD mediados pela internet, tomando como referência o caso dos atores envolvidos no curso de graduação em Administração, modalidade a distância, realizado pela ESCOLA/UFSB, no período de 2006 a 2011: professores, tutores, coordenadores de pólo, gestores e alunos.

Discutir este tema é relevante porque há necessidade de formar um número cada vez maior de profissionais qualificados, principalmente tutores, para atender à crescente demanda por programas de EAD. Outrossim, pode contribuir na resposta a perguntas do tipo: como deve ser a formação desses profissionais para atuar no ensino a distância? Qual o conteúdo dos cursos voltados a este fim? Quais os requisitos para que um tutor esteja apto a atuar em programas de EAD?

A atividade de tutoria, presencial ou a distância, ganhou notoriedade a partir do advento das modernas Tecnologias de Informação e Comunicação (TICs) e do já citado crescimento dos cursos de EAD.

Desta forma, entendendo as peculiaridades da EAD, busca-se uma resposta para o seguinte questionamento: qual é o papel de um tutor na atuação em programas de educação a distância mediados pela internet, como o curso de graduação em Administração, modalidade a distância, da ESCOLA/UFSB, edição de 2006 a 2011?

Assim, o objetivo geral do estudo é identificar e caracterizar o papel de tutores em cursos de EAD mediados pela internet, utilizando, como objeto de estudo, o curso de graduação em Administração, modalidade a distância, da ESCOLA/UFSB, edição de 2006 a 2011.

Esta pesquisa pretende se constituir em uma fonte de informação para auxiliar as 
instituições de ensino superior (IES), que possuem cursos na modalidade a distância, para selecionar, formar e capacitar seu corpo docente na atuação nestes programas especificamente em cursos mediados pela internet -, oferecendo ideias e subsídios relacionados ao papel de tutores em cursos nesta modalidade de ensino.

\section{O NOVO PROCESSO DE ENSINO NO CONTEXTO DA EAD}

Para Litwin (2001b), EAD é uma modalidade de ensino com uma maneira particular de criar um espaço para gerar, promover e implementar situações em que os alunos aprendam. Seu traço distintivo consiste na mediação das relações entre docentes e alunos. Isso significa substituir a proposta de uma assistência regular em aulas (presenciais) por uma nova, na qual os docentes ensinam e os alunos aprendem mediante situações não habituais (a distância), em espaços e tempos que não compartilham. A definição da autora destaca implicitamente diferenças objetivas da modalidade de EAD em relação à presencial e enfatiza o novo papel do docente, assim como a nova atitude requerida dos alunos.

Para superar barreiras geradas pela nova modalidade de ensino, caracterizada pelo uso mais intenso de tecnologias de informação e comunicação (TICs), especialmente a internet, vários recursos pedagógicos vêm sendo aplicados, com o objetivo de facilitar a construção do conhecimento e a eficácia dos aspectos organizacionais e administrativos: ágeis mecanismos de inscrição; distribuição eficiente dos materiais de estudo; informações precisas, eliminando obstáculos burocráticos do ensino convencional; atenção e orientação aos alunos, tanto no período inicial do curso, quanto no seu transcurso.

O papel do docente nos programas de EAD ganha importância à medida que o ensino se torna mais complexo, principalmente pelo maior uso das TICs. Outrossim, as formas de interagir com os alunos são cada vez mais intensas, recorrentes e fragmentadas; há necessidade maior de as equipes pedagógicas serem interdisciplinares e com domínio de aparato tecnológico (BELLONI, 1999). Nesta nova divisão do trabalho, de ensino na modalidade a distância, as funções docentes de selecionar, organizar e transmitir o conhecimento passam a constituir as atividades de planejamento, preparação e autoria dos currículos (cursos) e seus conteúdos, que formam a base dos materiais pedagógicos (livro-texto, vídeo-aulas, apostilas etc.); e a orientação da aprendizagem passa a ocorrer via tutoria a distância, em geral individualizada, principalmente com o apoio tecnológico de um Ambiente Virtual de Aprendizagem (AVA).

Sendo assim, fica claro que não se pode tratar o docente de forma genérica na EAD. Ele atua em papeis distintos, com peculiaridades que não podem ser desconsideradas. Tais atribuições constituem, portanto, um dos pontos críticos referentes a esta modalidade. A virtualização do processo de ensinar e as novas TICs fizeram com que os docentes tivessem que se adaptar a um novo modo de ensinar. $\mathrm{O}$ educador a distância deve reunir, então, qualidades de planejador, de pedagogo, de comunicador, e de conhecedor das características e das possibilidades dos meios instrucionais. Sua formação deve contemplar dimensões técnicas e humanas, além de conhecimentos relacionados ao contexto político-econômico e conhecimentos específicos. A missão mais difícil deste profissional é não deixar de considerar o aspecto afetivo do ensino, pois, independente da variedade de tecnologias à disposição dos alunos, estes sentem a necessidade de trocar informações e de se comunicar com o professor (MAIA, 2000; NISKIER, 1999).

Lévy (1999) afirma que, na EAD, o papel do professor estará centrado mais no acompanhamento e na gestão das aprendizagens; no incitamento à troca de saberes, na 
mediação relacional e simbólica, na pilotagem personalizada dos percursos de aprendizagem etc. Deverá ser um animador da inteligência coletiva dos grupos que estão a seu encargo. Estas descrições remetem, no entanto, mais ao papel do tutor do que do professor propriamente, considerando o que ocorre nos programas de EAD nas IES brasileiras. De fato, o professor deverá atuar como um formador, orientando o estudo e a aprendizagem; dando apoio psicossocial ao estudante; ensinando-o a pesquisar, a processar a informação e a aprender (BELLONI, 1999).

O presente estudo tem como foco um dos sujeitos envolvidos em programas de EAD mediados pela internet: o tutor - assim denominado nesta pesquisa, embora na literatura sejam encontradas diversas denominações para este profissional: instrutor, facilitador, mentor, orientador acadêmico, entre outras nominações.

A figura do tutor na EAD viveu, nas últimas duas décadas, uma significativa mudança em seu papel. Maggio (2001) destaca que, nas perspectivas tradicionais do ensino a distância, era comum sustentar que o tutor dirigia, orientava, apoiava a aprendizagem, mas não ensina.

Belloni (1999) também diferencia o papel do tutor, como sendo o profissional que orienta os alunos em seus estudos, esclarece dúvidas, explica questões relativas ao conteúdo da disciplina, e também participa das atividades de avaliação.

Em programas de EAD tradicionais, a constante ausência do docente era substituída pelos materiais de pacotes autodirigidos, fortemente sequenciados e pautados. A tarefa do tutor consistia em assegurar o cumprimento dos objetivos, oferecendo um apoio de controle e de ajuste de processos. Eram os materiais que ensinavam e o tutor desempenhava o papel de acompanhante funcional do sistema (MAGGIO, 2001). Atualmente, o tutor participa mais da aprendizagem dos alunos, embora algumas barreiras da EAD não tenham sido superadas. Dado que ainda existe um considerável número de tutores inexperientes, há um longo caminho a ser percorrido no sentido destes profissionais ganharem experiência, aprenderem como prever reações dos alunos aos eventos e como lidar com elas (MOORE e KEARSLEY, 2007).

Conforme Maia (2000), os melhores tutores a distância têm empatia e capacidade para entender as personalidades de seus alunos, mesmo quando filtradas pelas comunicações transmitidas tecnologicamente. É preciso que ele se coloque no lugar do aluno que vai aprender. Aos alunos com interesses comuns, os tutores devem oferecer atividades que facilitem as trocas de experiências. Devem também partilhar suas vivências acadêmicas e profissionais, e orientar para que se envolvam ativamente no processo de aprendizado. Devem criar um ambiente no qual os alunos aprendam a controlar e a gerenciar os conteúdos, relacionar os conteúdos com suas vidas e transformar as informações dos professores em conhecimento pessoal (MAIA, 2000; MOORE e KEARSLEY, 2007).

Na figura 01 seguinte, é possível ver a lista de funções em cursos de EAD, desempenhadas pelos tutores, na visão de Moore e Kearsley (2007). Essencialmente, classificam-se em quatro tipos de atividades: de ensino, nas quais o tutor ressalta certas partes do conteúdo do curso, orienta debates e interage com indivíduos e grupos; de progresso do aluno, em que o tutor analisa tarefas, as avalia, e fornece feedback, e depois registra no sistema; de apoio ao aluno, tendo em vista aspectos administrativos, técnicos ou de aconselhamento que o tutor realiza e depois encaminha a outros profissionais; de monitoramento dos alunos, por constituir os olhos e os ouvidos do sistema, em relação ao progresso dos alunos, constituindo a fonte mais confiável de informação. 
- .Elaborar o conteúdo do curso.

- Supervisionar e ser o moderador nas discussões.

- Supervisionar os projetos individuais e em grupo.

- Dar nota às tarefas e proporcionar feedback sobre o progresso.

- Manter registro dos alunos.

- Ajudar os alunos a gerenciar seu estudo.
- Motivar os alunos.

- Responder ou encaminhar questões administrativas

- Responder ou encaminhar questões técnicas

- Responder ou encaminhar questões de aconselhamento.

- Representar os alunos perante a Administração

- Avaliar a eficácia do curso.

Figura 01 - Funções dos tutores na EAD

Fonte: Adaptado de Moore e Kearsley, 2007, p. 149.

Niskier (2000) é bem específico ao listar as atividades inerentes ao tutor:

- comentar os trabalhos realizados pelos alunos;

- corrigir as avaliações escritas dos estudantes;

- ajudar os estudantes através de discussões e explicações para que compreendam os materiais dos cursos;

- responder às questões sobre a instituição;

- ajudar os estudantes para que planejem seus trabalhos;

- organizar círculos de estudo;

- fornecer informações por telefone, fax ou e-mail;

- supervisionar trabalhos práticos e projetos;

- apresentar-se em encontros periódicos;

- atualizar informações sobre o progresso dos estudantes;

- fornecer feedback aos coordenadores sobre os materiais dos cursos e as dificuldades dos estudantes; e

- servir de intermediário entre a instituição e os estudantes.

Conforme pode ser visto, quase todos os itens listados pelo autor são contemplados na figura 01. Todavia, deve ser destacado que o foco desta pesquisa vai além, não se restringindo a essas atividades.

\section{MÉTODO DE PESQUISA}

Neste capítulo são descritos os procedimentos metodológicos utilizados no estudo, partindo do delineamento e da estratégia de pesquisa, e depois apresentando as etapas, seus participantes, as técnicas de coleta, os instrumentos utilizados e a técnica que orientou a análise dos dados.

\subsection{CARACTERIZAÇÃO DA PESQUISA}

Esta pesquisa tem abordagem qualitativa e exploratória. $\mathrm{O}$ objetivo deste tipo de abordagem é prover percepções e compreensão do problema, assim como de seus fatores subjacentes. O caráter exploratório deste estudo fica evidente, pois ele objetiva proporcionar maior familiaridade com o problema, aprimorar idéias e descobrir intuições, com vistas a torná-lo mais explícito ou a construir hipóteses (GIL, 1995). A pesquisa também se configura como um estudo de caso, à medida que estuda exaustivamente um objeto, permitindo o seu amplo e detalhado conhecimento; no caso, o papel dos tutores para atuação num curso específico de graduação em Administração a distância.

Considerando essas possibilidades, define-se a presente pesquisa como um estudo de caso com triangulação de dados (YIN, 2005), pois ela envolve diferentes 
fontes - literatura, documentos, observação participante e entrevistas -, as quais serão melhor explicitadas ainda neste capítulo. A triangulação de dados atende ao princípio da utilização de várias fontes de dados quanto à coleta dos mesmos e, também de acordo com Yin (2001, p. 121), ao desenvolvimento de linhas convergentes de investigação.

Ainda segundo Yin (2005), apesar de os estudos de caso geralmente apresentarem questões do tipo "como?" e "por quê?", a presente pesquisa, ao salientar questões essencialmente exploratórias do tipo “o quê?" ou "quais?", pode ser considerada como sendo um estudo exploratório de caso.

\subsection{APRESENTAÇÃO DO CURSO DE GRADUAÇÃO EM ADMINISTRAÇÃO, MODALIDADE A DISTÂNCIA}

O curso de graduação, escolhido como objeto do presente estudo, foi planejado pelo Ministério da Educação (MEC) para auxiliar na implementação da política de ampliação do acesso ao ensino superior e para atender à demanda das empresas estatais em termos de qualificação dos seus servidores. Em 2005, foi firmada uma parceria com Universidades Federais e Estaduais que possuíam experiência em EAD, e, com o apoio do Banco do Brasil S/A, foi criado um curso de graduação em Administração, na modalidade a distância, que iniciou suas atividades no ano de 2006.

De acordo com o projeto pedagógico do curso, o mesmo visou a formar profissionais administradores com competências conceituais, técnicas e humanas, capazes de articular o conhecimento sistematizado com a ação profissional, objetivando a construção de um contexto organizacional eficaz e a sua transformação em oportunidades empreendedoras, fundamentado em responsabilidade social, justiça e ética, mediante utilização da tecnologia de ensino a distância, visando à ampliação dos recursos da Universidade Pública para um universo mais amplo de atendimento à sociedade. Para tanto, esta disponibilizou aos estudantes do curso vários polos regionais de estudo, com infraestrutura técnica e pedagógica, utilizados para as atividades presenciais e como base de apoio para os estudos durante o tempo do curso. O projeto pedagógico do curso previa que o desempenho de um aluno seria avaliado a partir do acompanhamento do seu percurso de estudo, em diálogos e entrevistas com os tutores; da produção de trabalhos escritos que possibilitassem uma síntese dos conhecimentos trabalhados; e da apresentação de resultados em estudos e pesquisas realizados semestralmente em seminários temáticos integradores.

Dispostas algumas informações pedagógicas do curso objeto desta pesquisa, o passo seguinte deste artigo é apresentar o ambiente virtual de aprendizagem (AVA) via qual os alunos, tutores, professores e coordenadores interagiram.

\subsection{O AMBIENTE VIRTUAL DE APRENDIZAGEM: PLATAFORMA NAVI}

A plataforma NAVi foi originalmente desenvolvida pelo Núcleo de Aprendizagem Virtual da ESCOLA/UFSB. Esse Núcleo era composto por professores, técnicos e gestores de diferentes áreas de conhecimento, para dar suporte teóricometodológico e apoio tecnológico ao desenvolvimento de cursos oferecidos na modalidade a distância, e com forte ênfase em processos interativos-cooperativos de aprendizagem. O objetivo do núcleo NAVi era buscar condições de consolidação da EAD na ESCOLA/UFSB, tanto para o apoio a cursos de extensão, graduação e pósgraduação na modalidade a distância, quanto para o enriquecimento das atividades de ensino presenciais. Uma apresentação mais completa do AVA NAVi pode ser encontrada em Klering \& Schröeder (2011). Auxiliavam professores, alunos, gestores e tutores de turmas (SCHRÖEDER, 2009).

A utilização do AVA NAVi foi fundamental para a realização do curso de 
graduação em Administração, modalidade a distância. Com exceção dos encontros presenciais que aconteceram nos polos regionais, todos os contatos feitos entre alunos e instituição, assim como as atividades curriculares realizadas a distância, ocorreram via utilização da plataforma NAVi.

\subsection{TÉCNICAS E INSTRUMENTOS DE PESQUISA}

\subsubsection{Entrevistas}

O acesso aos indivíduos ouvidos nesta fase da pesquisa foi possível pelo envolvimento dos pesquisadores dentro do próprio curso. Foram selecionados para entrevistas, com roteiros semiestruturados, tutores que trabalharam no curso durante os anos de 2008 a 2010; assim como alunos regularmente matriculados, membros da gestão do curso, coordenadores de polo e professores que atuaram em disciplinas no período de 2008 a 2010. O número de entrevistados, de cada um dos grupos, foi o seguinte:

- 13 tutores;

- 05 alunos;

- 02 gestores;

- 03 coordenadores de pólo; e

- 02 professores.

Em média, foram ministradas 08 disciplinas por ano no curso de Administração, em foco. Em cada disciplina atuaram, em média, 02 professores e 16 tutores. Sendo assim, trabalharam como tutores, anualmente, aproximadamente, 100 profissionais, considerando que alguns trabalharam em mais de uma disciplina, e o total médio de professores foi de 14. Todos trabalhavam em Porto Alegre e se encontravam todas as segundas e quartas-feiras para ministrar os chats em um dos laboratórios da ESCOLA/UFSB.

Os coordenadores de polo regionais eram atores permanentes na estrutura do curso. Havia 10 no total, sendo que 03 atuavam no polo da cidade de Porto Alegre e o restante, um em cada, nas demais cidades-polo do Estado do Rio Grande do Sul: Bagé, Caxias do Sul, Ijuí, Lajeado, Osório, Passo Fundo, Pelotas, Santa Maria e São Leopoldo. A estrutura de gestão do curso apresentava 01 pessoa na coordenação geral, 01 como gerente e mais 03 pessoas de apoio à gestão. Ao final do curso, havia cerca de 310 alunos ativos e remanescentes no curso.

Os participantes tutores da pesquisa foram escolhidos pelo critério da conveniência. O roteiro utilizado para a coleta dos dados dos diferentes atores envolvidos no curso era específico, mas as questões tratavam basicamente do mesmo tema: o papel do tutor.

\subsection{TRATAMENTO E ANÁLISE DOS DADOS}

Bardin (2004) define o método da análise de conteúdo como um conjunto de técnicas de análise das comunicações realizadas com o objetivo de obter indicadores (quantitativos ou não) que permitam a inferência de conhecimentos relativos às condições de produção e recepção de mensagens. Para tanto, são realizados procedimentos sistemáticos e objetivos de descrição do conteúdo das mensagens. A autora refere que um dos procedimentos mais usuais de análise é a categorização que, embora não obrigatória, é o centro da maioria dos procedimentos. No presente estudo, foram adotados os critérios sugeridos por Bardin (2004) para chegar a categorias que a autora citada considera como "boas": exclusão mútua; homogeneidade; pertinência; objetividade e produtividade.

$\mathrm{O}$ processo de categorização desta pesquisa seguiu critérios semânticos e 
léxicos. Inicialmente as entrevistas, já transcritas, foram lidas e foram selecionados trechos que se relacionavam com cada uma das questões do roteiro semiestruturado.

\section{ANÁLISE DOS RESULTADOS}

Para facilitar a ilustração e ao mesmo tempo para garantir o anonimato dos entrevistados, foram criados códigos para identificar de quem foram os trechos apresentados no decorrer da análise.

\subsection{DISCUSSÃO ACERCA DO PAPEL DO TUTOR}

A tutoria ganhou notoriedade na EAD à medida que a internet foi sendo incorporada às propostas de cursos a distância. Com a necessidade de atender a um número cada vez maior de estudantes, o suporte à aprendizagem passou a contar com a figura do tutor online.

Para se refletir sobre o papel do tutor em um curso de EAD mediado pela internet, como o caso em foco, é preciso compreender a percepção que os diversos atores envolvidos - gestores, professores, coordenadores de polo, alunos e dos próprios tutores - possuem acerca do tema.

Os entrevistados expressaram uma divergência forte, e ao mesmo tempo central, ao falar sobre as funções de um tutor. Parte deles não acredita que o tutor desempenhe somente papel de facilitador da aprendizagem. Eles acreditam que o tutor é um sujeito com responsabilidades iguais a de um professor presencial. Ele não é um simples executor de planejamentos; ao contrário, se constitui em uma referência para os alunos, uma figura em quem eles percebem disponibilidade, se apóiam e estabelecem relação de confiança.

Dentro deste grupo, alguns entrevistados disseram acreditar que os tutores devem possuir status de professores. A distinção entre eles deveria ser feita da seguinte forma: os atuais professores se chamariam "coordenadores da disciplina" e os tutores, sim, seriam chamados de professores. Mas não se trata apenas de capricho, vaidade. Eles justificam que a atual nomenclatura confere status inferior aos tutores, influenciando na autoridade, no peso de suas palavras, não apenas na relação entre tutores e alunos, mas também no relacionamento entre tutores e professores. Em função desta "inferioridade", eles não se sentem à vontade para dialogar horizontalmente com os professores, como pares, sobre as atividades do cotidiano da tutoria. Deveriam ser legitimados como professores, pois é a função que de fato desempenham.

A posição da maioria dos respondentes é de que o tutor deveria ser um facilitador, alguém que fornece o suporte necessário para que os alunos cheguem aos objetivos de aprendizagem seguindo um plano de ensino bem estruturado, com materiais próprios para a modalidade a distância. No entanto, por entender que muitas vezes (como no caso em foco) os conteúdos não são suficientemente claros e estruturados para o estudo autônomo dos alunos, a função exercida pelo tutor é mais que de tutor tradicional de cursos desenvolvidos na modalidade de EAD.

Vários entrevistados referiram que os conflitos que aparecem, muitas vezes, entre alunos e tutores, são reflexos dos conflitos entre esses e professores. Tais conflitos não são necessariamente negativos, mas podem constituir motivo para a busca de soluções, em conjunto com outros atores do processo.

Uma parcela dos entrevistados considera que os tutores tem restrições práticas, especialmente no que tange ao planejamento de disciplinas, normalmente realizado pelos professores-autores, porque os tutores assumem um direcionamento para a execução do planejamento definido por aqueles. Outrossim, de que suas responsabilidades são mais objetivas: ser um elo na comunicação entre os estudantes e 
os professores; orientar e incentivar os alunos; e transmitir conhecimentos.

Percebe-se, de maneira geral, que algumas respostas são contraditórias. Elas ressaltam que o tutor não poderia se restringir ao papel de facilitador para os alunos, mas, ao mesmo tempo, descrevem exemplos de atitudes diretamente ligadas a comportamentos mais instrumentais por parte dos tutores.

Outra constatação é de que os tutores são capazes de realizar um atendimento mais eficaz aos discentes. Para serem bem sucedidos, devem conhecer bem seus alunos: suas necessidades, seus projetos e suas dificuldades. Não se pode pensar em EAD desconsiderando o que os estudantes têm a contribuir para a construção dos saberes.

De fato, é complexo definir o papel do tutor e não há consenso entre os entrevistados, e mesmo dentro dos grupos de tutores, professores, gestores, coordenadores de pólo e alunos. No entanto, prevalece a opinião de que os tutores mais atuam como professores, especialmente pela autonomia e pelas responsabilidades atribuídas e assumidas, do que como tutores, conforme as funções referidas por Moore e Kearsley (2007) na figura 1 anterior, e por Niskier (2000). Esta percepção também é compartilhada pelos pesquisadores e autores deste estudo, que também participaram diretamente da experiência desenvolvida. Na prática, isso ocorreu pelo menos nas seguintes situações práticas do curso analisado:

- quando o tutor trabalhou em sintonia com os professores no planejamento de disciplinas, tendo autonomia e responsabilidade (delegadas) para interagir com os alunos e resolver problemas relativos ao seu cotidiano;

- em ocasiões em que não houve planejamento conjunto das atividades da disciplina e não foram firmadas bases de compromisso entre tutores e professores, quando então o tutor desempenhou o papel de professor por iniciativa própria, na tentativa de prever e solucionar potenciais conflitos nas interações com os alunos, e também por acreditar que os professores não estavam dispostos ou aptos a ajudá-los.

Verifica-se, assim, que há uma necessidade imperiosa para uma definição mais clara e formal das atribuições e responsabilidades dos professores-autores, assim como dos tutores, que de fato realizam um papel misto de professores e tutores segundo a concepção tradicional desses atores, em cursos desenvolvidos na modalidade de EAD, pelo menos como no caso estudado.

\section{CONSIDERAÇÕES FINAIS}

A discussão sobre o papel do tutor, apresentada na seção 4.1, é de grande relevância para os profissionais que atuam com educação, na modalidade a distância. Como visto na análise, o tutor é o protagonista no atendimento aos alunos. Ele está sempre na linha de frente, assumindo, segundo grande parte dos entrevistados, o papel do professor perante sua turma.

Ficou evidente, após a realização do estudo, que o tutor é o sujeito dentro da estrutura dos programas de EAD que mais se confronta com as consequências dos eventos. Quando se inicia uma aula síncrona mediada pela internet, por exemplo, não se sabe se a conexão permanecerá estável; como será o comportamento dos alunos nas interações com os colegas e tutores; ou se os vídeos previstos para os alunos assistirem no decorrer da aula funcionarão da maneira adequada para todos os envolvidos. Exigese dele as várias funções de um gestor, que não se limitam à função de execução: de planejamento, de organização, de coordenação, de execução e de controle. Esta é uma constatação interessante e importante desta pesquisa, que vem ao encontro da percepção de que o papel de um tutor, em situações como no caso estudado, extrapola o papel 
previsto tradicionalmente pela literatura. Porque, de fato, assumem um papel de professor-administrador perante suas turmas, alguém que se depara com situações de EAD complexas - eventos - e que precisa tomar decisões acertadas, mobilizando e combinando os recursos (pessoais, de conhecimentos ou de habilidades) adequados a cada circunstância.

Assim, um nome mais apropriado para descrever o real papel de um tutor, tal como exercido no caso estudado, conviria e poderia ser de professor-tutor.

\section{REFERÊNCIAS}

BARDIN, Laurence. Análise de Conteúdo. 3.ed.. Lisboa: Edições 70, 2004.

BELLONI, Maria Luiza. Educação a distância. Campinas, SP: Autores Associados, 1999.

GIL, Antonio Carlos. Como elaborar projetos de pesquisa. 4. ed. São Paulo: Atlas, 2006.

GIL, Antonio Carlos. Métodos e técnicas de pesquisa social. São Paulo: Atlas, 1995.

KLERING, L. R.; SCHRÖEDER, C. S. Desenvolvimento de um Ambiente Virtual de Aprendizagem à luz do Enfoque Sistêmico. In: Tecnologias de Administração e Contabilidade, Curitiba, v.1, n. 2, art 1, pp. 42-54, Jul/Dez 2011.

LÉVY, Pierre. Cibercultura. - São Paulo: Ed. 34, 1999. 264 p.

LITWIN, Edith. O bom ensino na educação a distância. In: LITWIN, Edith (Org.). Educação a distância: temas para debate de uma nova agenda educativa. Porto Alegre: Artmed Editora, 2001a.

LITWIN, Edith. Das tradições à virtualidade. In: LITWIN, Edith (Org.). Educação a distância: temas para debate de uma nova agenda educativa. Porto Alegre: Artmed Editora, 2001b.

MAIA, Carmem. Ead.br. São Paulo: Anhembi Morumbi, 2000. 136 p.

MAIA, Carmem; MATTAR, João. ABC da Ead. - 1.ed. - São Paulo: Pearson Prentice Hall, 2007.

MAGGIO, Mariana. O tutor na educação a distância. In: LITWIN, E. Educação a distância: temas para debate de uma nova agenda educativa. Porto Alegre: Artmed editora, 2001.

MOORE, Michael G.; KEARSLEY, Greg. Educação a distância: uma visão integrada. São Paulo: Thomson Learning, 2007.

NAKAYAMA, Marina Keiko; SILVEIRA, Ricardo Azambuja. Ensino a distância nos programas de capacitação. In: BITTENCOURT, Cláudia (Org). Gestão contemporânea de pessoas: novas práticas, conceitos tradicionais. - Porto Alegre: Bookman, 2004. 528 p.

NISKIER, Alberto. A educação a distância: a tecnologia da esperança. - 2. ed. - São Paulo: Loyola, 2000.

ROESCH, Sylvia Maria Azevedo. Projetos de estágio e de pesquisa em Administração. São Paulo: Atlas, 1999, 2.ed.

SCHRÖEDER, Christine da Silva. Educação a distância e mudança organizacional na Escola de Administração da UFRGS: uma teoria substantiva. 2009. $252 \mathrm{f}$. Tese (Doutorado em Administração) - Programa de Pós-Graduação em Administração, Escola de Administração, Universidade Federal do Rio Grande do Sul, Porto Alegre, 2009.

YIN, Robert K. Estudo de caso. Planejamento e métodos. 3.ed. Porto Alegre: Bookman, 2001. 212 p. 